\title{
A preliminary study of schema therapy for young adults with high-functioning autism spectrum disorder: a single-arm, uncontrolled trial
}

\author{
Fumiyo Oshima ${ }^{1 *}$, Tomokazu Murata ${ }^{1}$, Toshiyuki Ohtani ${ }^{1,2}$, Mikuko Seto $^{1}$ and Eiji Shimizu ${ }^{2}$
}

\begin{abstract}
Objective: Psychological problems associated with isolation and mistrust are common among young adults with autism spectrum disorder (ASD). Schema therapy (ST) has recently been shown to be effective against chronic personality problems of various mental disorders, including personality disorders. This pilot clinical trial aimed to explore the feasibility and acceptability of ST in young adults with high-functioning ASD.
\end{abstract}

Results: Following the intervention, a significant reduction in early maladaptive schemas and improvements in quality of life and social adjustment were observed. ST may be feasible and is applicable to young adults with HF-ASD.

Trial registration UMIN000014535; registered on July 11, 2014

Keywords: Autism spectrum disorder, Schema therapy, Social adjustment, Quality of life

\section{Introduction}

Autism spectrum disorder (ASD) is a neurodevelopmental disorder with persistent deficits in social communication and social interaction based on the Diagnostic and Statistical Manual of Mental Disorders, Fifth Edition (DSM-5) [1]. ASD adults tend to have difficulties with social functioning, contributing to a poor quality of life (QOL) [2]. ASD children diagnosed before the age of 10 years tend to have a higher psychosocial QOL than those who are not [3].

Unfortunately, most high-functioning ASD (HF-ASD) individuals remain undiagnosed at early ages because of high functioning [4], and they do not receive appropriate support, as symptoms remain unnoticed for the same reason $[5,6]$. Unawareness of their ASD traits could

\footnotetext{
*Correspondence: f_oshima@chiba-u.jp

${ }^{1}$ Research Center for Child Mental Development, Chiba University, 1-8-1

Inohana, Chuouku, Chiba 260-8670, Japan

Full list of author information is available at the end of the article
}

result in an inferiority complex and self-stigmatization, which may increase depression and anxiety [7].

Cognitive behavioral therapy (CBT) is frequently used to treat ASD related symptoms. A meta-analytic review revealed that cognitive behavioral therapy effectively treats anxiety in children with ASD [8]. However, the effects of cognitive-behavioral therapy on depression in children and adults [9] and anxiety [10,11] in adults with ASD are inconsistent. Several studies have shown that ASD after puberty is characterized by strong selfstigmatization due to chronic social isolation [12]. Such a self-stigma corresponds to an early maladaptive schema (EMS) in terms of schema therapy. It is known that patients with ASD have significantly higher EMS than healthy people, resulting in a negative impact on mental health [13]. Since CBT is a symptom-specific treatment, it does not focus on EMS. Therefore, improving CBT for ASD individuals is clinically important. 
Schema therapy (ST) [14], an innovative and integrative psychotherapy model, is used to treat those who face difficulties with personality disorder diagnoses [15-20]. ST is composed of an EMS, schema mode (SM), limited reparenting, and core emotional needs [21, 22]. EMS is an excessively generalized cognitive and emotional system composed of innate features and early childhood experiences. When an individuals' core needs are unfulfilled in early childhood, they can form multiple EMS, which develop a SM that temporarily comes to the fore and dominates their presentation, resulting in difficulties in interpersonal relationships [23]. We previously confirmed that HF-ASD individuals have more EMS than general controls [24]. As EMS are assumed to be the core of the psychopathology of HF-ASD and personality disorders, learning how to change EMS into more adaptive ones, and utilizing their adaptive coping responses, is the ultimate goal of ST [25]. The purpose of ST is to cultivate a more constructive "healthy adult mode" (instead of schema mode) toward environmental stimuli by gratifying patients' core needs using "limited reparenting." ST, a structured type of psychotherapy, is effective [15, $26,27]$ and suitable for many psychiatric disorders; HFASD adults are considered suitable for ST, as they generally benefit from structured settings [28]. In this study, we identified EMSs specific to HF-ASD individuals [24]. However, studies on the clinical feasibility and acceptability of ST for HF-ASD are limited. Thus, this pilot study used ST for adults with HF-ASD and examined its feasibility and acceptability in improving patients' EMS and $\mathrm{SM}$ and the consequent improvements in QOL and social adjustment.

\section{Main text}

\section{Materials and methods}

This was a single-arm preliminary study with an open trial design in a Japanese clinical setting.

\section{Participants}

Participants $(n=13)$ were recruited through psychiatrist referral at the Safety and Health Organization, Chiba University, and Chiba University Hospital, Chiba, Japan. The inclusion criteria were as follows: age between 18 and 40 years, intelligence quotient (IQ) $\geq 80$ (Wechsler Adult Intelligence Scale III [29]), and an ASD diagnosis based on the Autism Diagnostic Interview-Revised [30] and/or the Autism Diagnostic Observation ScheduleSecond Edition [31]. The Mini-International Neuropsychiatric Interview [32] was used to evaluate comorbid psychiatric conditions. The exclusion criteria were: a history of substance abuse, active suicidality, and severe mental and physical conditions. Participants were adults of average intelligence with ASD who could respond on their own initiative after understanding the reason for obtaining research consent.

\section{Procedures}

Recruitment, treatment, and data collection were conducted between September 2014 and March 2018; the trial flow chart is shown in Fig. 1. Each weekly session lasted 50 min (Additional file 1: Table S1). A follow-up interview was conducted 12 weeks after the intervention completion (37th week).

\section{Treatment outcome}

The primary outcome measures were the Global Assessment Functioning (GAF) Scale [33], an interview rating of social functioning and the World Health Organization quality of life assessment brief (WHO QOL-BREF) [34], which was a self-rating scale measuring subjective feeling of social adaptiveness and QOL. The secondary outcomes were the scores of the Young Schema Questionnaire-Short Form 3 (YSQ-SF) [35] and the Schema Mode Inventory (SMI) [36], which measure EMS and the schema modes of patients, respectively. Other outcome variables of comorbid symptoms, such as depression, anxiety, and obsessive-compulsive symptoms, were assessed by the Beck Depression Inventory II (BDIII) [37], the State-Trait Anxiety Inventory (STAI) [38], Liebowitz Social Anxiety Scale (LSAS) [39], and Obsessive-Compulsive Inventory [40], respectively. Permission was not needed to use these questionnaires.

\section{Analysis}

Data were analyzed using repeated-measures analysis of variance (rANOVA) with time as the independent variable. In addition, a paired t-test adjusted by a Bonferroni correction was used for pairwise comparisons. For the primary outcomes and other comorbid symptom measurements, the adjusted $\alpha$ value was $\alpha=0.05 / 3 / 9=0.002$. For the secondary outcomes, the adjusted $\alpha$ value was $0.05 / 3 / 23=0.0007$ for YSQ-SF and $0.05 / 3 / 16=0.001$ for SMI. Effect sizes were calculated for changes in scale scores between time points (Cohen's $d$ ). All analyses were conducted using SPSS for Windows version 23 (IBM, Armonk, NY, USA).

\section{Results}

\section{Patients' demographics and baseline data}

Of the 13 patients, one was excluded, and two dropped out of the study, leaving 10 patients (Fig. 1). The participants were aged between 20 and 39 years and met the DSM-5 criteria for ASD (Table 1 and Additional file 2: Table S2). 


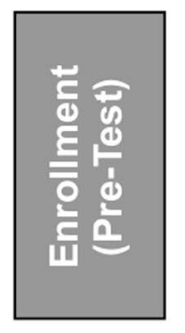

\section{Assessed for eligibility $(n=13)$}
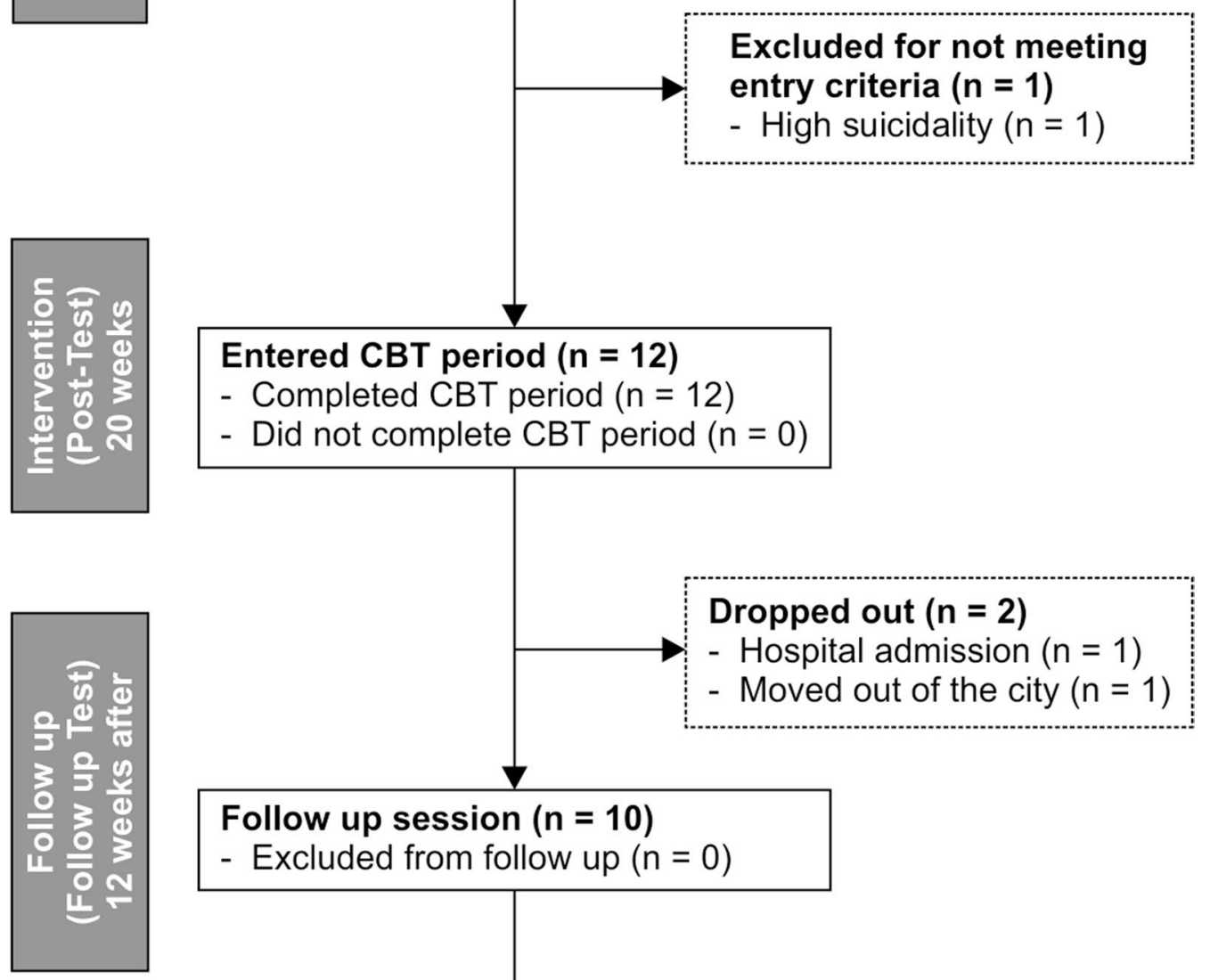

\section{Entered CBT period $(n=12)$}

- Completed CBT period $(n=12)$

- Did not complete CBT period $(n=0)$

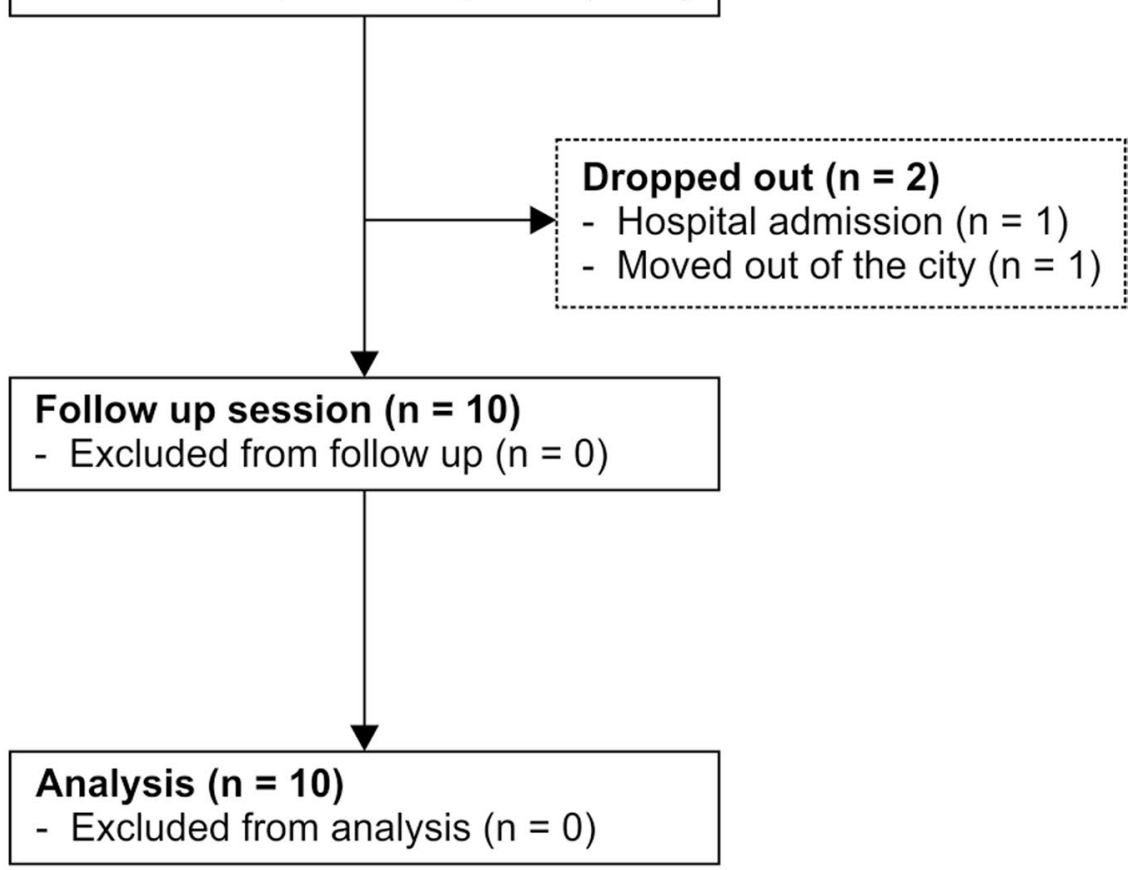

Fig. 1 CONSORT flow chart of the clinical trial

\section{Treatment outcomes}

The rANOVA revealed a significant main effect of time on the primary outcome, GAF. A post hoc analysis revealed that there were significant differences between pre-and post-treatment $(p<0.001, d=3.30)$ and between pre-treatment and follow-up $(p<0.001, d=3.35)$ (Table 2). Additionally, the main effect of time for WHO
QOL-BREF was significant; however, the post hoc analyses results did not remain significant between each time point after the correction.

Regarding the secondary outcomes, the rANOVA revealed a significant effect of time on the YSQ-SF (total score), disconnection and rejection, impaired autonomy and performance, impaired limits (over-vigilance and 
Table 1 Baseline demographic and clinical characteristics

\begin{tabular}{|c|c|}
\hline Variable & $\begin{array}{l}\text { Mean (SD)/frequency } \\
(\%)\end{array}$ \\
\hline Age & $26.8(6.39)$ \\
\hline \multicolumn{2}{|l|}{ Sex } \\
\hline Female & $5(50 \%)$ \\
\hline Male & $5(50 \%)$ \\
\hline \multicolumn{2}{|l|}{ Education } \\
\hline Master & $2(20 \%)$ \\
\hline Bachelor & $7(70 \%)$ \\
\hline High school & $1(10 \%)$ \\
\hline \multicolumn{2}{|l|}{ Employment } \\
\hline Student & $7(70 \%)$ \\
\hline Part timer & $1(10 \%)$ \\
\hline Unemployed & $2(20 \%)$ \\
\hline \multicolumn{2}{|l|}{ Diagnosis } \\
\hline ASD + OCD & $4(40 \%)$ \\
\hline $\mathrm{ASD}+\mathrm{ADHD}$ & $1(10 \%)$ \\
\hline ASD + DEP & $5(50 \%)$ \\
\hline \multicolumn{2}{|l|}{ ADI-R } \\
\hline Quality of reciprocal social interaction & $16(4.22)$ \\
\hline Communication & $13.3(4.37)$ \\
\hline Repetitive, restricted, and stereotyped patterns of behavior & $3.2(1.75)$ \\
\hline Abnormalities of behavior evident at or before 36 months & $1.8(1.14)$ \\
\hline \multicolumn{2}{|l|}{ ADOS-2 } \\
\hline Communication & $3.8(1.48)$ \\
\hline Reciprocal social interaction & $7(2.54)$ \\
\hline Imagination/creativity & $1.4(0.52)$ \\
\hline Restricted and repetitive behaviors & $1.2(0.63)$ \\
\hline \multicolumn{2}{|l|}{ WAIS-3 } \\
\hline VIQ & $120.8(10.6)$ \\
\hline $\mathrm{PIQ}$ & $117.7(11.04)$ \\
\hline $\mathrm{FIQ}$ & $120(9.51)$ \\
\hline VC & $119.7(12.31)$ \\
\hline $\mathrm{PO}$ & $120(12.75)$ \\
\hline WM & $112.6(11.16)$ \\
\hline PS & $109.7(19.29)$ \\
\hline
\end{tabular}

$A D H D$ attention deficit hyperactivity disorder, ADI-R Autism Diagnostic Interview-Revised, ADOS-2 Autism Diagnostic Observation Schedule-2, DEP depression, FIQ full scale IQ, OCD obsessive-compulsive disorder, PIQ performance IQ, PO perceptual organization, $P S$ perceptual organization, VC verbal comprehension, VIQ verbal IQ, WAIS-3 The Wechsler Adult Intelligence Scale-3, WM working memory

inhibition), social isolation/alienation schema, failure schema, dependence/incompetence schema, emotional inhibition schema, approval-seeking/recognition-seeking schema, negativity/pessimism schema, and punitiveness schema scores, but not on other subscales (Additional file 3: Table S3). The Bonferroni post hoc test showed a significant difference between pre-treatment and the follow-up ( $p=0.00048, d=1.01$ ) for the YSQ-SF (total score). Similarly, for disconnection and rejection, a significant difference was found between post-treatment and follow-up $(p=0.00026, d=0.34)$. There was also a significant difference for impaired limits (over-vigilance and inhibition) between pre-treatment and follow-up $(p=0.00002, d=0.63)$. In addition, for the emotional inhibition schema and the negativity/pessimism schema, although the ANOVA showed a significant main effect of time, the Bonferroni post hoc test did not show any significance.

Regarding the SMI, the repeated-measures ANOVA revealed a significant main effect of time for the scores of the adaptive, maladaptive, vulnerable child, angry child, enraged child, impulsive child, undisciplined child, happy 
Table 2 Changes in each evaluated item before ST, after ST, and at follow-up

\begin{tabular}{|c|c|c|c|c|c|c|c|}
\hline \multirow[t]{2}{*}{ Variable } & \multirow{2}{*}{$\begin{array}{l}\text { Pre-ST } \\
\text { Mean (SD) }\end{array}$} & \multirow{2}{*}{$\begin{array}{l}\text { Post-ST } \\
\text { Mean (SD) }\end{array}$} & \multirow{2}{*}{$\begin{array}{l}\text { Follow-up } \\
\text { Mean (SD) }\end{array}$} & \multirow[t]{2}{*}{$F$} & \multicolumn{3}{|l|}{ Cohen's $d$} \\
\hline & & & & & $\begin{array}{l}\text { Pre-ST vs. } \\
\text { post-ST }\end{array}$ & $\begin{array}{l}\text { Post-ST vs. } \\
\text { follow-up }\end{array}$ & $\begin{array}{l}\text { Pre-ST vs. } \\
\text { follow-up }\end{array}$ \\
\hline GAF & $45.90(10.82)$ & $76.00(7.06)^{\mathrm{a}}$ & $76.20(6.83)^{c}$ & $F(1.3,11.67)=151.65^{* *}$ & 3.30 & 0.03 & 3.35 \\
\hline QOL & $65.20(16.03)$ & $75.70(14.28)^{a}$ & $78.50(12.77)$ & $F(1.21,10.87)=9.93^{* *}$ & 0.69 & 0.21 & 0.92 \\
\hline BDI-II & $27.70(17.54)$ & $16.70(13.94)$ & $13.00(11.76)$ & $F(1.16,10.4)=9.64^{* *}$ & 0.70 & 0.29 & 0.99 \\
\hline STAI (state) & $45.20(9.47)$ & $49.70(8.21)$ & $41.50(6.92)^{b}$ & $F(2,18)=3.93^{*}$ & 0.51 & 1.08 & 0.45 \\
\hline STAI (trait) & $55.80(14.16)$ & $53.00(10.53)$ & $47.50(8.82)$ & $F(2,18)=3.56^{*}$ & 0.23 & 0.57 & 0.70 \\
\hline $\mathrm{OCl}$ & $67.70(30.94)$ & $59.40(27.39)$ & $49.70(23.15)$ & $F(1.17,10.49)=3.98$ & 0.29 & 0.38 & 0.66 \\
\hline LSAS_Total & $62.70(22.60)$ & $62.80(27.53)$ & $50.70(18.64)$ & $F(1.2,10.81)=2.71$ & 0.00 & 0.52 & 0.58 \\
\hline LSAS_fear/anxiety & $35.90(13.54)$ & $35.40(15.18)$ & $27.20(9.32)$ & $F(2,18)=5.22^{*}$ & 0.04 & 0.65 & 0.75 \\
\hline LSAS_escape & $26.80(13.23)$ & $27.40(13.70)$ & $23.50(11.21)$ & $F(1.27,11.46)=0.59$ & 0.05 & 0.31 & 0.27 \\
\hline
\end{tabular}

BDI-II, Beck Depression Inventory-II; LSAS (Total score), Total items from the Liebowitz Social Anxiety Scale; LSAS (Fear/Anxiety), Fear and anxiety items from the Liebowitz Social Anxiety Scale; LSAS (Avoidance), Avoidance items from the Liebowitz Social Anxiety Scale; STAl (State), State items from the State-Trait Anxiety Inventory; STAI (Trait), Trait items from the State-Trait Anxiety Inventory; OCl, Obsessive Compulsive Inventory

${ }^{* *} p<0.01, * p<0.05$ calculated using analysis of variance

${ }^{a}$ Significant difference between pre- and post-intervention values ( $p<0.05$, Bonferroni corrected)

${ }^{\mathrm{b}}$ Significant difference between post-intervention and follow-up values

' Significant difference between pre-intervention and follow-up values $(p<0.05$, Bonferroni corrected)

child, compliant surrender, detached protector, selfaggrandizer, punitive parent, and demanding parent, and healthy adult modes (Additional file 4: Table S4).

Conversely, there was no significant difference in the detached self-soothing or bullying and attack modes. Bonferroni post hoc tests showed a significant difference between pre-treatment and follow-up for the maladaptive $(p=0.00051, d=1.57)$, enraged child, $(p=0.00012$, $d=1.86)$, undisciplined child ( $p=0.00066, d=0.97)$, and demanding parent modes $(p=0.00010, d=1.10)$.

Regarding other outcomes, significant effects of time were observed for BDI-II, STAI-state and -trait, and LSAS fear/anxiety; however, post hoc comparison with Bonferroni correction did not remain significant between each time point.

\section{Discussion}

This study examined the feasibility and acceptability of ST for HF-ASD adults. Furthermore, this study provided a proof-of-concept where adults with high-functioning ASD had improved QOL and social functioning after receiving ST. ST aims to improve chronic psychological maladjustment rather than specific symptoms of individuals. The psychological maladjustment of adults with ASD includes isolation, which is anxiety regarding exclusion, and at a behavioral level, withdrawal and avoidance are common [5]. ST does not encompass the element of improving communication skills, but it may restore a sense of trust in others, which is the foundation of communication. For example, at the post-intervention, seven patients indicated social participation, such as returning to school or removing themselves from self-imposed isolation and receiving employment support.

This study showed a reduction in the YSQ total score, disconnection and rejection subscale, and impaired limits subscale. Moreover, ST for HF-ASD may have improved an individuals' disconnected feelings towards others or the social environment and enhanced their self-control abilities. Regarding the subscales of EMS, individuals with ASD scored higher than individuals without social isolation, failure, and dependence-incompetence [29]. The results of this study showed that these three EMS (social isolation, failure, and dependence-incompetence) were significantly reduced after the intervention. Moreover, they are considered to influence communication style and social relationships [29], and improvement in EMS and social functioning may be important ST outcomes for HF-ASD. Additionally, we found that ST for HF-ASD showed a significant improvement in several subscales of SMI. Interestingly, these changes were statistically significant only from pre-intervention to follow-up, not from pre- to post-intervention. Since the schema mode is more stable than EMS, changes in the former may have delayed the effects. When considering the underlying mechanisms of delayed improvement in SMI, decreased scores in the enraged child, undisciplined child, and demanding parent mode may have reduced individual irritability and aggressive behavior, leading to less social interactionrelated problems. Moreover, the maladaptive coping mode can enhance avoidance behaviors and/or overadaptations, and the reduced maladaptive coping mode via ST may enable individuals to participate socially. 
ST targets EMS at the deepest cognition level and is considered better equipped to enable dysfunctional schematic processing changes. For example, ST showed clinical efficacy in treatment-resistant patients, such as those with personality disorders [41]. It has been reported that some adult patients with ASD have a self-stigma against ASD and are highly resistant to treatment [5]. ST may enhance ASD adults' awareness and acceptance of their ASD, which may also influence their social adaptiveness. Finally, we did not observe any significant improvement in comorbid symptoms after ST. Since baseline scores for those measurements were not high compared with patients with major depressive, anxiety, and obsessivecompulsive disorders, those with comorbid symptoms may not have improved.

\section{Conclusion}

This study highlights that ST may be feasible for ASD participants and is applicable to individuals with HFASD. Additional data is required to ensure the clinical benefit of ST for individuals with HF-ASD. Future clinical trials should incorporate the following: (a) RCTs should be conducted to provide evidence of the effects of ST on adults with ASD, (b) homogeneity of the target population should be ensured by reducing the number of juxtaposed psychiatric disorders to one, and (c) not only self-rating scales but also other-rating indicators should be incorporated into the evaluation.

\section{Limitations}

There are several limitations to this study. First, this study's sample size was small and had some bias in the demographics of the subjects (mental disorders other than ASD, IQ, and age). Therefore, the results might have been biased and should be considered carefully.

Second, the study design should be improved from a single-arm to a randomized control design. This singlearm study did not incorporate controls during the secondary diagnoses, thereby restricting the comparability of this study with other psychological interventions in terms of the clinical efficacy of ST on social adaptations. Finally, it may be difficult to exclusively determine the efficacy of ST on social adaptiveness from this study. Since ST involves psychoeducation regarding ASD traits, the component of psychoeducation may influence social adaptiveness along with ST.

\section{Abbreviations}

ASD: Autism spectrum disorder; BDI-II: Beck Depression Inventory II; CBT: Cognitive-behavioral therapy; DSM-5: Diagnostic and statistical manual of mental disorders; EMS: Early maladaptive schema; GAF: Global assessment functioning; HAM: Healthy adult mode; HF-ASD: High-functioning autism spectrum disorder; IQ: Intelligence quotient; RCTs: Randomized control trial; QOL: Quality of life; SMI: Schema Mode Inventory; ST: Schema therapy; WHO
QOL-BREF: World Health Organization Quality Of Life Assessment Brief; YSQ-SF: Young Schema Questionnaire Short Form 3.

\section{Supplementary Information}

The online version contains supplementary material available at https://doi. org/10.1186/s13104-021-05556-1.

Additional file 1: Table S1. Contents of schema therapy (ST) for highfunctioning autism spectrum disorder (ASD).

Additional file 2: Table S2. Sociodemographic data.

Additional file 3: Table S3. Changes in Scores of Young Schema Questionnaire (YSQ) before and after ST at follow-up.

Additional file 4: Table S4. Changes in Schema Mode Inventory (SMI) before and after ST at follow-up.

\section{Acknowledgments}

Our deep appreciation is extended to Ida Shaw at the Schema Therapy Institute Midwest-Indianapolis and to Aki Tsuchiyagaito at the Laureate Instituto for Brain Research, Tulsa, for their immense contribution to this investigation.

\section{Authors' contributions}

Study concept and design: FO and ES. Statistical analysis for study design: TM. Drafting of the manuscript: FO and ES. Critical revision of the manuscript: HO. Study therapists: FO and MS. Acquisition of data: MS. Study supervision: ES. All authors have approved the submitted version and any substantially modified version that involves the author's contribution to the study. All authors have agreed to be personally accountable for their own contributions and to ensure that questions related to the accuracy or integrity of any part of the work, even ones in which the author was not personally involved, are appropriately investigated, resolved, and the resolution documented in the literature. All authors read and approved the final manuscript.

\section{Funding}

The study was supported by the Grant-in-Aid for Young Scientists (B) (15K17290) of the Japan Society for the Promotion of Science in Japan. The funders had no role in the design of the study and collection, analysis, and interpretation of data, or in the writing of the manuscript.

\section{Availability of data and materials}

The datasets used and/or analyzed during the current study are available from the corresponding author on reasonable request.

\section{Declarations}

\section{Ethics approval and consent to participate}

This trial was approved by the Chiba University Clinical Research Ethical Review Committee (No.1867). Written informed consent was obtained from the participants by providing a consent form approved by the Chiba University Clinical Research Ethical Committee, following a verbal explanation of the trial along with the consent form. All personal information (including anonymized data) were treated as confidential. Participants could access these data after the follow-up upon request. This clinical trial was registered on the University Hospital Medical Information Network Center (No. UMIN000014535). The Chiba University Clinical Research Ethical Committee reviewed the study protocol. All sessions and psychological examinations were provided free of charge to the participants.

Consent to publish

Not applicable.

Competing interests

The authors declare that they have no competing interests. 


\section{Author details}

${ }_{1}^{1}$ Research Center for Child Mental Development, Chiba University, 1-8-1 Inohana, Chuouku, Chiba 260-8670, Japan. ' 2 Safety and Health Organization, Chiba University, Chiba, Japan.

Received: 16 November 2020 Accepted: 7 April 2021 Published online: 29 April 2021

\section{References}

1. American Psychiatric Association, DSM-5 Task Force. Diagnostic and statistical manual of mental disorders: DSM- $5^{\mathrm{TM}}$. 5 th ed. Washington: American Psychiatric Publishing, Inc.; 2013. https://doi.org/10.1176/appi. books.9780890425596.

2. Lever AG, Geurts HM. Psychiatric co-occurring symptoms and disorders in young, middle-aged, and older adults with autism spectrum disorder. J Autism Dev Disord. 2016. https://doi.org/10.1007/s10803-016-2722-8.

3. Kamio Y, Inada N, Koyama T. A nationwide survey on quality of life and associated factors of adults with high-functioning autism spectrum disorders. Autism. 2013. https://doi.org/10.1177/1362361312436848.

4. Bargiela S, Steward R, Mandy W. The experiences of late-diagnosed women with autism spectrum conditions: an investigation of the female autism phenotype. J Autism Dev Disord. 2016. https://doi.org/10.1007/ s10803-016-2872-8

5. Calzada LR, Pistrang N, Mandy WPL. High-functioning autism and Asperger's disorder: utility and meaning for families. J Autism Dev Disord. 2012. https://doi.org/10.1007/s10803-011-1238-5.

6. Murphy CM, Wilson CE, Robertson DM, Ecker C, Daly EM, Hammond N, et al. Autism spectrum disorder in adults: diagnosis, management, and health services development. Neuropsychiatr Dis Treat. 2016. https://doi. org/10.2147/NDT.S65455.

7. Hayes J, Ford T, Rafeeque H, Russell G. Clinical practice guidelines for diagnosis of autism spectrum disorder in adults and children in the UK: a narrative review. BMC Psychiatry. 2018. https://doi.org/10.1186/ s12888-018-1800-1.

8. Perihan C, Burke M, Bowman-Perrott L, Bicer A, Gallup J, Thompson J, et al. Effects of cognitive behavioral therapy for reducing anxiety in children with high functioning ASD: a systematic review and meta-analysis. J Autism Dev Disord. 2020. https://doi.org/10.1007/s10803-019-03949-7.

9. Menezes M, Harkins C, Robinson MF, Mazurek MO. Treatment of depression in individuals with autism spectrum disorder: a systematic review. Res Autism Spectr Disord. 2020. https://doi.org/10.1016/j.rasd.2020. 101639.

10. Russell AJ, Jassi A, Fullana MA, Mack H, Johnston K, Heyman I, et al. Cognitive behavior therapy for comorbid obsessive-compulsive disorder in high-functioning autism spectrum disorders: a randomized controlled trial. Depress Anxiety. 2013. https://doi.org/10.1002/da.22053.

11. Tsuchiyagaito A, Hirano Y, Asano K, Oshima F, Nagaoka S, Takebayashi Y, et al. Cognitive-behavioral therapy for obsessive-compulsive disorder with and without autism spectrum disorder: gray matter differences associated with poor outcome. Front Psychiatry. 2017. https://doi.org/10. 3389/fpsyt.2017.00143.

12. Ruiz Calzada L, Pistrang N, Mandy WP. High-functioning autism and Asperger's disorder: utility and meaning for families. J Autism Dev Disord. 2012. https://doi.org/10.1007/s10803-011-1238-5.

13. Someki F, Torii M, Brooks PJ, Koeda T, Gillespie-Lynch K. Stigma associated with autism among college students in Japan and the United States: an online training study. Res Dev Disabil. 2018. https://doi.org/10.1016/j.ridd. 2018.02.016.

14. Young J. Cognitive therapy for personality disorders: a schema- focused approach. Sarasota: Professional Resource Exchange, Inc.; 1990.

15. Carter JD, Mclntosh W, Jordan J, Porter RJ, Frampton CM, Joyce PR. Psychotherapy for depression: a randomized clinical trial comparing schema therapy and cognitive behavior therapy. J Affect Disord. 2013. https://doi. org/10.1016/j.jad.2013.06.034.

16. Giesen-Bloo J, van Dyck R, Spinhoven P, van Tilburg W, Dirksen C, van Asselt T, et al. Outpatient psychotherapy for borderline personality disorder: randomized trial of schema-focused therapy vs transference-focused psychotherapy. Arch Gen Psychiatry. 2006. https://doi.org/10.1001/archp syc.63.6.649.
17. van Asselt AD, Dirksen CD, Arntz A, Giesen-Bloo JH, van Dyck R, Spinhoven $\mathrm{P}$, et al. Out-patient psychotherapy for borderline personality disorder: cost-effectiveness of schema-focused therapy $v$. transferencefocused psychotherapy. Br J Psychiatry. 2008. https://doi.org/10.1192/bjp. bp.106.033597.

18. Farrell JM, Shaw IA, Webber MA. A schema-focused approach to group psychotherapy for outpatients with borderline personality disorder: a randomized controlled trial. J Behav Ther Exp Psychiatry. 2009. https://doi. org/10.1016/j.jbtep.2009.01.002

19. Nadort M, Arntz A, Smit JH, Giesen-Bloo J, Eikelenboom M, Spinhoven $P$, et al. Implementation of outpatient schema therapy for borderline personality disorder: study design. BMC Psychiatry. 2009. https://doi.org/ 10.1186/1471-244X-9-64.

20. Masley SA, Gillanders DT, Simpson SG, Taylor MA. A systematic review of the evidence base for schema therapy. Cogn Behav Ther. 2012. https:// doi.org/10.1080/16506073.2011.614274.

21. Schmidt NB, Joiner TE. Global maladaptive schemas, negative life events, and psychological distress. J Psychopathol Behav Assess. 2004. https:// doi.org/10.1023/B:JOBA.0000007457.95008.d2.

22. Halvorsen M, Wang CE, Eisemann M, Waterloo K. Dysfunctional attitudes and early maladaptive schemas as predictors of depression: a 9-year follow-up study. Cognit Ther Res. 2010. https://doi.org/10.1007/ s10608-009-9259-5.

23. Young JE, Klosko J, Weishaar ME. Schema therapy: a practitioners guide. New York: Guilford; 2003.

24. Oshima F, Iwasa K, Nishinaka H, Shimizu E. Early maladaptive schemas and high- functioning Autism Spectrum Disorders in adults. Evid Psychother. 2015;15:191-205.

25. Renner F, Arntz A, Leeuw I, Huibers M. Treatment for chronic depression using schema therapy. Clin Psychol (New York). 2013. https://doi.org/10. 1111/cpsp.12032.

26. Cockram DM, Drummond PD, Lee CW. Role and treatment of early maladaptive schemas in Vietnam veterans with PTSD. Clin Psychol Psychother. 2010. https://doi.org/10.1002/cpp.690.

27. Simpson SG, Morrow E, van Vreeswijk M, Reid C. Group schema therapy for eating disorders: a pilot study. Front Psychol. 2010. https://doi.org/10. 3389/fpsyg.2010.00182.

28. Vuijk R, Arntz A. Schema therapy as treatment for adults with autism spectrum disorder and comorbid personality disorder: protocol of a multiple-baseline case series study testing cognitive-behavioral and experiential interventions. Contemp Clin Trials Commun. 2017. https:// doi.org/10.1016/j.conctc.2017.01.001.

29. Ryan JJ, Sattler JM, Lopez SJ. Age effects on Wechsler Adult Intelligence Scale-III subtests. Arch Clin Neuropsychol. 2000. https://doi.org/10.1016/ S0887-6177(99)00019-0.

30. Lord C, Rutter M, Le Couteur A. Autism diagnostic interview-revised: a revised version of a diagnostic interview for caregivers of individuals with possible pervasive developmental disorders. J Autism Dev Disord. 1994. https://doi.org/10.1007/BF02172145.

31. Lord C, Rutter M, DiLavore P, Risi S, Gotham K, Bishop S. Autism diagnostic observation schedule (ADOS-2). 2nd ed. Los Angeles: Western Psychological Corporation; 2012.

32. Sheehan DV, Lecrubier Y, Harnett Sheehan K, Janavs J, Weiller E, Keskiner A, et al. The validity of the Mini International Neuropsychiatric Interview (MINI) according to the SCID-P and its reliability. Eur Psychiatry. 1997. https://doi.org/10.1016/S0924-9338(97)83297-X.

33. Aas IM. Global Assessment of Functioning (GAF): properties and frontier of current knowledge. Ann Gen Psychiatry. 2010. https://doi.org/10.1186/ 1744-859X-9-20.

34. The WHOQOL Group. The World Health Organization quality of life assessment (WHOQOL): development and general psychometric properties. Soc Sci Med. 1998. https://doi.org/10.1016/S0277-9536(98)00009-4.

35. Oshima F, Iwasa K, Nishinaka H, Suzuki T, Umehara S, Fukui I, et al. Factor structure and reliability of the Japanese version of the Young Schema Questionnaire Short Form. Rev Int J Psycol Ter Psycol. 2018;18:99-109.

36. Lobbestael J, van Vreeswijk M, Spinhoven P, Schouten E, Arntz A. Reliability and validity of the short Schema Mode Inventory (SMI). Behav Cogn Psychother. 2010. https://doi.org/10.1017/S1352465810000226.

37. Beck AT, Steer RA, Brown GK. BDI-II, Beck depression inventory: manual. San Antonio: Psychological Corporation; 1996. 
38. Spielberger CD, Gorsuch RL, Lushene RE. STAI manual for the State-trait anxiety inventory ("self-evaluation questionnaire"). California: Consulting Psychologists Press; 1970.

39. Liebowitz MR. Social phobia. Mod Probl Pharmacopsychiatry. 1987;22:141-73.

40. Foa EB, Kozak MJ, Salkovskis PM, Coles ME, Amir N. The validation of a new obsessive-compulsive disorder scale: the obsessive-compulsive inventory. Psychol Assess. 1998. https://doi.org/10.1037/1040-3590.10.3. 206.
41. Taylor CDJ, Bee P, Haddock G. Does schema therapy change schemas and symptoms? A systematic review across mental health disorders. Psychol Psychother. 2017. https://doi.org/10.1111/papt.12112.

\section{Publisher's Note}

Springer Nature remains neutral with regard to jurisdictional claims in published maps and institutional affiliations.
Ready to submit your research? Choose BMC and benefit from:

- fast, convenient online submission

- thorough peer review by experienced researchers in your field

- rapid publication on acceptance

- support for research data, including large and complex data types

- gold Open Access which fosters wider collaboration and increased citations

- maximum visibility for your research: over $100 \mathrm{M}$ website views per year

At BMC, research is always in progress.

Learn more biomedcentral.com/submissions 